\title{
Stress Among Bachelor Physical Therapy Students in Israel during Clinical Practice and Its Association with Academic Achievements- Results of a Longitudinal Study
}

Tamar Jacob

Ariel University Center of Samaria, tamar@ariel.ac.il

Ofira Einstein

Ariel University, ofira@ariel.ac.il

Follow this and additional works at: https://nsuworks.nova.edu/ijahsp

Part of the Medicine and Health Sciences Commons

\section{Recommended Citation}

Jacob T, Einstein O. Stress Among Bachelor Physical Therapy Students in Israel during Clinical Practice and Its Association with Academic Achievements- Results of a Longitudinal Study. The Internet Journal of Allied Health Sciences and Practice. 2016 Jan 01;14(1), Article 9.

This Manuscript is brought to you for free and open access by the College of Health Care Sciences at NSUWorks. It has been accepted for inclusion in Internet Journal of Allied Health Sciences and Practice by an authorized editor of NSUWorks. For more information, please contact nsuworks@nova.edu. 


\title{
Stress Among Bachelor Physical Therapy Students in Israel during Clinical Practice and Its Association with Academic Achievements- Results of a Longitudinal Study
}

\begin{abstract}
Purposes: This study aimed 1) to evaluate perceived stress of a cohort of bachelor physical therapy (PT) students from Ariel University in Israel across three clinical practice periods; 2 ) to evaluate the relationship between perceived stress and academic achievements; 3 ) to evaluate the relationship between students' perceived stress and clinical practice periods' order and content; and 4) to identify clinical and sociodemographic variables related to perceived stress. Methods: A longitudinal study was conducted among a cohort of undergraduate PT students during their first, second, and third clinical practice assignments. Data were collected using an online questionnaire. The Perceived Stress Scale 10 (PSS) and the Scale for Assessing Academic Stress (SAAS) were used to evaluate perceived stress. A ten-degree Visual Analogue Scale (VAS) was used to evaluate perceived difficulty. Students' grade point averages from the first three years of study were considered academic achievements. An ANOVA was used to evaluate the relationship between perceived stress and academic achievements, and between clinical practice order and area and the socio-demographic characteristics. Results: A total of 39 undergraduate physical therapy students participated in the study. The degrees of PSS and SAAS were higher than those reported previously in undergraduate PT students. Perceived stress was not related to academic achievement, clinical practice order or area, or to socio-demographic characteristics. Conclusions: Participation in clinical practice in general might be a stressful situation, but no specific clinical or socio-demographic factors that might be a source of higher levels of perceived stress were identified. As undergraduate students are away from the campus during clinical practice periods, it is suggested that clinical instructors, who are in daily contact with the students, should receive guidance regarding the ways to identify individuals who present signs of increased stress and the types of strategies that can help students cope with stress in real time.
\end{abstract}

\section{Author Bio(s)}

Tamar Jacob, PT, MPH, PhD, is the head of the Masters' program at the Physical Therapy Department in Ariel University, Israel. She is a senior lecturer and a registered physical therapist. She has been engaged in education of physical therapy students for over thirty years.

Ofira Einstein, BPT, PhD, is the head of the Physical Therapy Department in Ariel University, Israel. She is a senior lecturer and a registered physical therapist. Her PhD degree is in Neurobiology. Her current scientific work focuses on physical exercise and brain inflammatory diseases.

\section{Acknowledgements}

The authors would like to thank the students Bosmat Gutman, Michal Linkovsky, Ortal Moyal and Ina Gofman for their contribution in data collection. 


\title{
TIAHSP \\ The Internet Joưnal of Allied Health Sciences and Practice
}

Dedicated to allied health professional practice and education

Vol. 14 No. 1 ISSN 1540-580X

\section{Stress Among Bachelor Physical Therapy Students in Israel during Clinical Practice and Its Association with Academic Achievements- Results of a Longitudinal Study}

\author{
Tamar Jacob, PT, MPH, PhD \\ Ofira Einstein, BPT, PhD
}

Ariel University

Israel

\begin{abstract}
Purposes: This study aimed 1) to evaluate perceived stress of a cohort of bachelor physical therapy (PT) students from Ariel University in Israel across three clinical practice periods; 2) to evaluate the relationship between perceived stress and academic achievements; 3 ) to evaluate the relationship between students' perceived stress and clinical practice periods' order and content; and 4) to identify clinical and socio-demographic variables related to perceived stress. Methods: A longitudinal study was conducted among a cohort of undergraduate PT students during their first, second, and third clinical practice assignments. Data were collected using an online questionnaire. The Perceived Stress Scale 10 (PSS) and the Scale for Assessing Academic Stress (SAAS) were used to evaluate perceived stress. A ten-degree Visual Analogue Scale (VAS) was used to evaluate perceived difficulty. Students' grade point averages from the first three years of study were considered academic achievements. An ANOVA was used to evaluate the relationship between perceived stress and academic achievements, and between clinical practice order and area and the socio-demographic characteristics. Results: A total of 39 undergraduate physical therapy students participated in the study. The degrees of PSS and SAAS were higher than those reported previously in undergraduate PT students. Perceived stress was not related to academic achievement, clinical practice order or area, or to socio-demographic characteristics. Conclusions: Participation in clinical practice in general might be a stressful situation, but no specific clinical or socio-demographic factors that might be a source of higher levels of perceived stress were identified. As undergraduate students are away from the campus during clinical practice periods, it is suggested that clinical instructors, who are in daily contact with the students, should receive guidance regarding the ways to identify individuals who present signs of increased stress and the types of strategies that can help students cope with stress in real time.
\end{abstract}

\section{INTRODUCTION}

Health care students and physical therapy (PT) students in particular are liable to experience high levels of perceived stress. ${ }^{1-4}$ Reasons for this stress may be related to the expansion of these professions in recent years and the rate and amount of the new knowledge professionals need to absorb. ${ }^{5}$ In addition, health care studies include the acquisition of clinical skills that demand a significant amount of education practice hours. Furthermore, education programs must ensure that students acquire not only knowledge and skills, but also graduate-level capabilities, such as clinical problem solving, effective interpersonal interactions, and skills for lifelong learning. All of these require many hours of theoretical and practical study, and consequently, may lead students to feel they are functioning under a great deal of pressure. ${ }^{5}$

The impact of stress on learning is particularly significant in the context of professional education because it has the potential to disturb human functioning, including the capacity to absorb information. High levels of psychological distress among health care students may contribute not only to impaired academic performance, but also to attrition, cynicism, and lack of empathy when working with patients. 6,7 
Stress Among Bachelor Physical Therapy Students in Israel during Clinical Practice and Its Association with Academic

Research regarding perceived stress among PT students is mainly focused on preclinical studies and their findings are inconclusive. For example, the study by Walsh et al on stress and psychological morbidity pointed to the emotional vulnerability of a significant proportion of PT students. In that study, about one quarter of all students scored above the General Health Questionnaire threshold, indicating psychological morbidity levels higher than those reported in the general population. ${ }^{4} \mathrm{~A}$ longitudinal study of students enrolled in a three-year nursing program found that their levels of distress were higher than those of either PT or occupational therapy students. ${ }^{3}$ The most important predictor of psychological distress in that study was the "level of psychological distress at the beginning of the study." However, two other studies conducted among PT students from UK, Australia, Sweden, and Israel found that the main sources of stress were related to high academic demands. ${ }^{1,8}$ In one of these studies, Israeli PT students experienced lower levels of stress than their peers in either Australia or Sweden. ${ }^{8}$

Physical therapy educational programs include clinical practice that usually lasts about one quarter of the program. During this period, students are required to integrate knowledge from various areas (e.g., basic sciences, practical skills, sociology, and psychology) into clinical settings under the close supervision of a clinical instructor. Several studies have discussed the behaviors that are required for PT students to succeed in clinical practice. ${ }^{9-11}$ May et al identified 10 abilities that are not part of the profession's core of knowledge or technical skills: critical thinking, communication, problem solving, interpersonal skills, responsibility, professionalism, use of constructive feedback, effective use of time and resources, stress management, and commitment to learning. ${ }^{9}$ Stress management was defined as "the ability to identify sources of stress and to develop and implement effective coping behaviors." A few years later, Hayes et al sorted the abilities that PT students need to apply in a clinical setting into cognitive and non-cognitive categories. ${ }^{10}$ Knowledge and psychomotor skills were attributed to the cognitive category, while professional behavior and communication were attributed to the non-cognitive category. Hayes et al concluded that clinical instructors need to identify unacceptable behaviors and discuss them with the students. Based on these studies, Jette and Portney tested the construct validity of a model for professional behavior among PT students. ${ }^{11}$ They identified seven factors which corresponded fairly well to the 10 abilities described above.

Although clinical practice periods might be a stressful time for many students, neither of the latest studies addressed stress management directly. 9,10 Moreover, the issue of perceived stress during clinical practice has scarcely been evaluated in the professional literature. One early study suggested an approach that addresses the issue of stress at the interface between preclinical and clinical PT education. ${ }^{12}$ Cupit assumed that much of the stress experienced by students relates to the new behavioral responses required of them during the clinical component of the training. It was suggested that negotiating an acceptable contract related to student and tutor might be helpful and applicable in the clinical environment. Furthermore, in a study conducted among Japanese PT students, the authors found that stressful interpersonal events experienced during the clinical practice still influenced the level of students' stress responses even after the practical training was completed. ${ }^{13}$

In a recent study, Jette et al discussed ideas for improving the quality of PT clinical education. ${ }^{14}$ Their recommendations relate to issues of structure, process, and outcomes of clinical practice, but not to the psychological impact of this period. Given that perceived stress during clinical practice might be high and might interfere with students' functioning, this issue requires further attention. ${ }^{17}$ It is particularly important to target specific stress management strategies in light of relatively recent evidence of the effectiveness of such strategies among students in a PT doctoral program and among students in general. ${ }^{16,17}$

\section{Evaluating Perceived Stress among Students}

Previous studies have described different approaches to evaluate perceived stress, measured globally, or as event-specific perceived stress. Examples of tools that measure global stress are the Perceived Stress Scale (PSS) and the Beck Depression Inventory, which measure the degree to which participants appraise their individual situation as stressful. $18,19 \mathrm{An}$ example of a tool that measures event-specific stress is the Scale for Assessing Academic Stress (SAAS), which measures perceived stress specifically in relation to one's academic environment. ${ }^{20}$ Measurements from both categories can be complementary, and therefore, it is reasonable to use one of each category to evaluate students' stress.

The four-year health sciences program in Israel in which participants of the current study were enrolled offers a bachelor's degree in PT. One quarter of the program ( 960 hours) is dedicated to clinical practice, which consists of three compulsory modules (based on the clinical environment: a general hospital, an ambulatory clinic, and a rehabilitation center) and one elective module. The first clinical practice module takes place during the second semester of the third year, and the remaining three modules are completed during the fourth and final year of the program. Each compulsory module lasts eight weeks (full-time, i.e., 280 hours). Clinical practice assignments are located outside the campus, at various sites throughout the country, and an effort is made to place students at a reasonable distance from their homes ( $<1$ hour drive). To facilitate student's integration and coping, several efforts are made prior and during clinical practice. Before the start of clinical practice, students take a course in which they receive information about the nature and content of this period, about their duties, and about the nature of the interactions that will take

(C) The Internet Journal of Allied Health Sciences and Practice, 2016 
place between them, the clinical instructors, and the rest of the clinical staff. During the clinical practice, a faculty member is assigned to oversee students' performance during the module and is responsible for maintaining contact with students. This faculty is familiar with the students, the clinical placements, and the instructors. When determining students' clinical practice placements, this faculty usually takes into consideration factors related to students' and instructors' personalities in an attempt to make the best possible match.

In addition, each student is visited at the clinical placement by one of the faculty members. Students are encouraged to share their experiences, feelings, and difficulties with their clinical instructors or with the faculty member during the visit or by phone. The university provides some educational and psychological support to all attending students. However, there is no screening system to identify students in extreme stress. Thus, requests for support are usually based on students' self-referral.

Clinical instructors evaluate students' progress using two of the three available evaluation tools: the clinical evaluation form, a final practical examination, and/or a case report. Based on the assumption that students experience higher levels of perceived stress during their first clinical practice module, it was decided that the practical examination would not be used to evaluate students completing their first clinical practice so as to avoid the risk of increased stress.

Clinical instructors and faculty are aware of individual students' complaints of high levels of stress during the clinical practice modules. For ethical reasons, the PT department policy is not to provide information to clinical instructors about students' pre-clinic academic achievements or personal problems. Students are advised to provide such information on their own, as they see fit. However, there is evidence that high achievers who have higher scholastic capacity are calmer, more emotionally stable, and face reality more readily than do low achievers. ${ }^{17}$ Therefore, it might be assumed that low achievers are more likely to perceive higher levels of stress than high achievers. It is questionable whether divulging information to clinical instructors regarding students' achievement levels prior to the clinical practice would serve to increase instructors' awareness of potentially vulnerable students.

In light of the above, this study aimed to provide an in-depth examination of perceived stress among a cohort of PT students enrolled in three compulsory, clinical practice modules. The information garnered from the current study was expected to indicate factors that might help predict PT students' predisposition to high levels of perceived stress before the students' clinical practice assignments and placements are determined. The following assumptions were made: 1) Students experience higher levels of stress during the first clinical practice module and at ambulatory clinics. 2) Students with lower academic achievements might perceive higher levels of stress compared to their peers with higher academic achievements. 3) Students with families, students employed in a job unrelated to PT studies, and those less satisfied with their clinical practice placement might perceive higher levels of stress.

Thus, the aims of this study were as follows: 1) to evaluate perceived stress of a cohort of PT students undergoing training in three different clinical practice modules; 2) to evaluate the relationship between perceived stress and academic achievements; 3 ) to evaluate the relationship between perceived stress and clinical practice characteristics; and 4) to evaluate the relationships between perceived stress and socio-demographic characteristics.

\section{METHODS}

\section{Population}

A longitudinal survey was administered among a cohort of undergraduate bachelor PT students, enrolled in three compulsory clinical practice modules during the academic year of 2012-2013 at Ariel University in Israel. The class included 51 students, 37 $(72.5 \%)$ women and $14(27.5 \%)$ men, with an average age of 25.9 years (SD \pm 2.7$)$. It was assumed that this cohort could represent a typical class of bachelor PT students at this university.

\section{Data Collection}

Data, collected via an electronic questionnaire, included measures of perceived stress and perceived difficulty of the clinical experience (perceived difficulty), socio-demographic details, and variables related to the clinical practice.

Measurements of perceived stress and difficulty: The PSS and the SAAS were used to evaluate perceived stress. ${ }^{18,20}$ The PSS is used to measure the degree to which situations in one's life are appraised as stressful. ${ }^{21} \mathrm{It}$ comprises ten categorical items that relate to frequency of stress in different situations. Responses on the PSS items indicated the frequency with which the students experienced certain feelings and thoughts during the last month. For example, item 1 asks: "In the last month, how often have you been upset because of something that happened unexpectedly?" The total numeric score on this questionnaire can range between 0 and 40. Evidence for the superiority of the PSS over several other scales used for measuring psychological symptoms has been described previously.22 The items included in the PSS are quite general in nature and hence relatively free of specific content.

(C) The Internet Journal of Allied Health Sciences and Practice, 2016 
Cohen and Williamson (1988) argued that this measurement technique prevents a single event from overshadowing other less significant ones. ${ }^{21}$ The authors found that the PSS provided better predictions than did life-events scales of psychological symptoms or measuring students' utilization of health services in college. ${ }^{21,22}$ Norms of PSS scores obtained from a probability sample of undergraduate college students in the United States presented an average level of 13 on a scale from 0 to $40 .{ }^{21}$

The SAAS is a measure of perceived stress specifically related to academic stress. ${ }^{12}$ It comprises 30 "yes/no" items grouped into five functional sections: cognitive, emotional, physical, social, and motivational functioning. Participants were asked to review a list of 30 functions and to mark each function that was relevant to them in the past month, among them, "difficulty concentrating, headaches, difficulty solving problems, hesitate to ask questions." The SAAS, evaluated using a population sample of high school and college students, was found to have high test-retest reliability (.88 over a period of one month), adequate internal consistency (ranging between .30 and .81 Cronbach's alpha), and adequate validity (the correlation coefficient of SAAS with Academic Anxiety for Children and with Beck Depression Inventory were found to be .54 and .43, respectively). The total SAAS scores between 0 to 30 had the ability to yield normally distributed data on academic stress. Norms for 50 boys and girls (attending grade 12) were 5.63 \pm 2.01 and $4.85 \pm 1.96$, respectively. ${ }^{21}$

A high score on both scales points to a high degree of PS. However, there is no categorization of high, moderate, or low degrees of perceived stress or SAAS. Therefore, students who presented perceived stress scores higher than the mean by 1 SD were considered more stressed than their peers. Both questionnaires were translated into Hebrew using a translation-retranslation procedure. Participants were also asked about their global sense of "perceived difficulty of the clinical experience" (perceived difficulty) using a 10 degree Likert-type scale ( $1=$ not difficult at all; $10=$ very difficult).

Measurements of Academic achievements: Academic achievements were defined by the grade point average (GPA) of the first two years and of the first semester of the third year of the program. The latter is the semester immediately before the first clinical practice module, during which two of the main clinical integrative courses are taught.

Clinical experience variables: Variables related to the clinical experience included order of clinical practice assignment, clinical field, satisfaction with clinical guidance, the degree of interest raised during that period, and faculty availability. Satisfaction variables were evaluated on a 4-point Likert-type scale, ranging from 1 (very low) to 4 (to a great extent).

Socio-demographic variables: The socio-demographic variables included in the study were age, gender, family status, paid employment, and duration of the commute to the location of the clinical practice facility. ${ }_{1}^{1,21,23}$

\section{Procedures}

Online questionnaires were administered to all students at the midterm of the first, second, and third clinical practice modules. The first period took place during the second semester of the third year of the PT program and the last two during the fourth year. This particular standardized timing of data collection was chosen to avoid the direct influence of end-of semester examinations. The students were informed about the volunteer nature of the study and that they were free to decline to participate. All participants signed a form to indicate their informed consent before completing the questionnaire. The study was approved by the ethics committee of Ariel University.

\section{Data Analysis}

As there is no information about the sensitivity of the PSS and the SAAS, the measurements provide information relative to the cohort and to data from previous studies. Analysis of variance was used to evaluate differences between groups for continuous variables (e.g., PSS, SAAS), while Chi square test was used for categorical variables. Means and $95 \%$ confidence intervals were evaluated in order to estimate differences.

Pearson correlation was used to evaluate correlations between PSS, SAAS, perceived difficulty, and academic achievements. For all the analyses, $P$ values $\leq .05$ were considered statistically significant. Data were analyzed using SPSS software.

\section{RESULTS}

A total of 39 students completed the questionnaire during the first clinical practice module. Among those who did not, 7 were not referred to clinical practice (4 failed a prerequisite course, 2 were on maternity leave, and 1 quit the program) and 5 others did not respond. Thirty one participants completed the questionnaires during the second and the third clinical practice modules. Three of the students took a leave of absence due to personal reasons, 1 quit the clinical practice in the first week, and 4 did not respond. Thus, the participant response rate was nearly $80 \%$, and the group of consistent responders was similar in terms of age and gender distribution. The majority of the students were referred to either general hospitals, ambulatory clinics, or rehabilitation centers

(C) The Internet Journal of Allied Health Sciences and Practice, 2016 
Table 1: Characteristics of Participants' from Three Clinical Practice Modules*

\begin{tabular}{|c|c|c|c|c|c|}
\hline & & & \multicolumn{3}{|c|}{ Clinical Practice Module } \\
\hline Characteristic & Subgroups & Total Class & $1^{\text {st }}$ & $2^{\text {nd }}$ & $3^{\text {rd }}$ \\
\hline $\mathrm{N}$ & & 51 & 39 & 31 & 31 \\
\hline Response Rate (\%) & & $100 \%$ & 76.5 & 79.5 & 79.5 \\
\hline $\begin{array}{l}\text { Years of } \mathrm{Age} \\
\text { Mean } 95 \% \mathrm{Cl}\end{array}$ & & $\begin{array}{l}25.9 \\
25.2-26.6\end{array}$ & $\begin{array}{l}26.7 \\
25.8-27.5\end{array}$ & $\begin{array}{l}27.7 \\
26.8-28.5\end{array}$ & $\begin{array}{l}27.68 \\
26.8-28.5\end{array}$ \\
\hline Gender & $\begin{array}{l}\mathrm{M} \\
\mathrm{F}\end{array}$ & $\begin{array}{l}14(27.5) \\
37(72.5)\end{array}$ & $\begin{array}{c}9(23.1) \\
30(76.9)\end{array}$ & $\begin{array}{c}9(29.0) \\
22(71.0)\end{array}$ & $\begin{array}{c}9(29.0) \\
22(71.0)\end{array}$ \\
\hline Family status & \multicolumn{2}{|l|}{$\begin{array}{l}\text { Single } \\
\text { Married } \\
\text { Married + children }\end{array}$} & $\begin{array}{l}23(59.0) \\
9(23.1) \\
7(17.9)\end{array}$ & $\begin{array}{l}15(48.4) \\
9(29.0) \\
6(19.4)\end{array}$ & $\begin{array}{l}15(48.4) \\
8(25.8) \\
7(22.4)\end{array}$ \\
\hline \multicolumn{2}{|c|}{$\begin{array}{l}\text { Changed place of residence due to clinical } \\
\text { practice site }\end{array}$} & & $12(30.8)$ & $5(19.4)$ & $8(25.8)$ \\
\hline $\begin{array}{l}\text { Driving time to clinical } \\
\text { placement }\end{array}$ & $\begin{array}{l}<1 \text { hour } \\
\geq 1 \text { hour }\end{array}$ & & $\begin{array}{l}21(56.8) \\
16(43.2)\end{array}$ & $\begin{array}{l}21(70.0) \\
9(30.0)\end{array}$ & $\begin{array}{l}18(58.1) \\
13(41.9)\end{array}$ \\
\hline \multicolumn{2}{|c|}{ Paid work during clinical practice } & & $18(46.2)$ & $21(67.7)$ & $23(74.2)$ \\
\hline Field of clinical practice & \multicolumn{2}{|l|}{$\begin{array}{l}\text { General Hospital } \\
\text { Ambulatory Clinic } \\
\text { Rehabilitation }\end{array}$} & $\begin{array}{l}24(61.5) \\
15(38.5) \\
-\quad\end{array}$ & $\begin{array}{c}7(22.6) \\
9(29.0) \\
15(48.4)\end{array}$ & $\begin{array}{c}6(20.0) \\
10(33.3) \\
13(43.3)\end{array}$ \\
\hline $\begin{array}{ll}\text { Satisfaction } & \text { with } \\
\text { assignment } & \end{array}$ & $\begin{array}{l}\text { Yes } \\
\text { No }\end{array}$ & & $\begin{array}{c}34(87.2) \\
5(12.8)\end{array}$ & $\begin{array}{l}29(93.5) \\
2(6.5)\end{array}$ & $\begin{array}{c}27(87.1) \\
4(12.9)\end{array}$ \\
\hline $\begin{array}{l}\text { Degree of interest in } \\
\text { clinical coursework area }\end{array}$ & $\begin{array}{l}\text { Very much } \\
\text { Much } \\
\text { Moderate } \\
\text { Low }\end{array}$ & & $\begin{array}{l}17(43.6) \\
14(35.9) \\
5(12.8) \\
3(7.7)\end{array}$ & $\begin{array}{c}6(20.0) \\
12(40.0) \\
12(40.0)\end{array}$ & $\begin{array}{l}13(41.9) \\
11(36.5) \\
4(12.9) \\
3(9.7)\end{array}$ \\
\hline $\begin{array}{l}\text { Degree of satisfaction } \\
\text { with clinical guidance }\end{array}$ & $\begin{array}{l}\text { Very much } \\
\text { Much } \\
\text { Moderate }\end{array}$ & & $\begin{array}{c}18(46.2) \\
14(35.9) \\
6(15.4)\end{array}$ & $\begin{array}{c}13(41.9) \\
10(32.3) \\
6(19.4)\end{array}$ & $\begin{array}{c}15(48.4) \\
11(35.5) \\
5(16.1)\end{array}$ \\
\hline
\end{tabular}

*Number present $\mathbf{n}(\%)$ unless otherwise stated

Perceived stress and difficulty during clinical practice: The average means of PSS, SAAS, and perceived difficulty for all 3 clinical practice periods were 19.5, 7.6, and 7.0, respectively. At each period, there were between 5-7 individual students whose perceived stress rates on both perceived stress measurements were (at least) 1 SD from the mean (Table 2). In general, different students indicated a high level of perceived stress for each of the three modules. Only one student indicated perceived stress scores higher than the mean by (at least) $1 \mathrm{SD}$ for all 3 clinical practice modules, and 2 students indicated the same for 2 modules. For each of the modules, PSS and SAAS scores correlated significantly with each other and with perceived difficulty (Table 3). 
Table 2: Perceived Stress throughout Three Clinical Practice Modules and Frequencies of Students with Perceived Stress Levels 1 SD above Mean

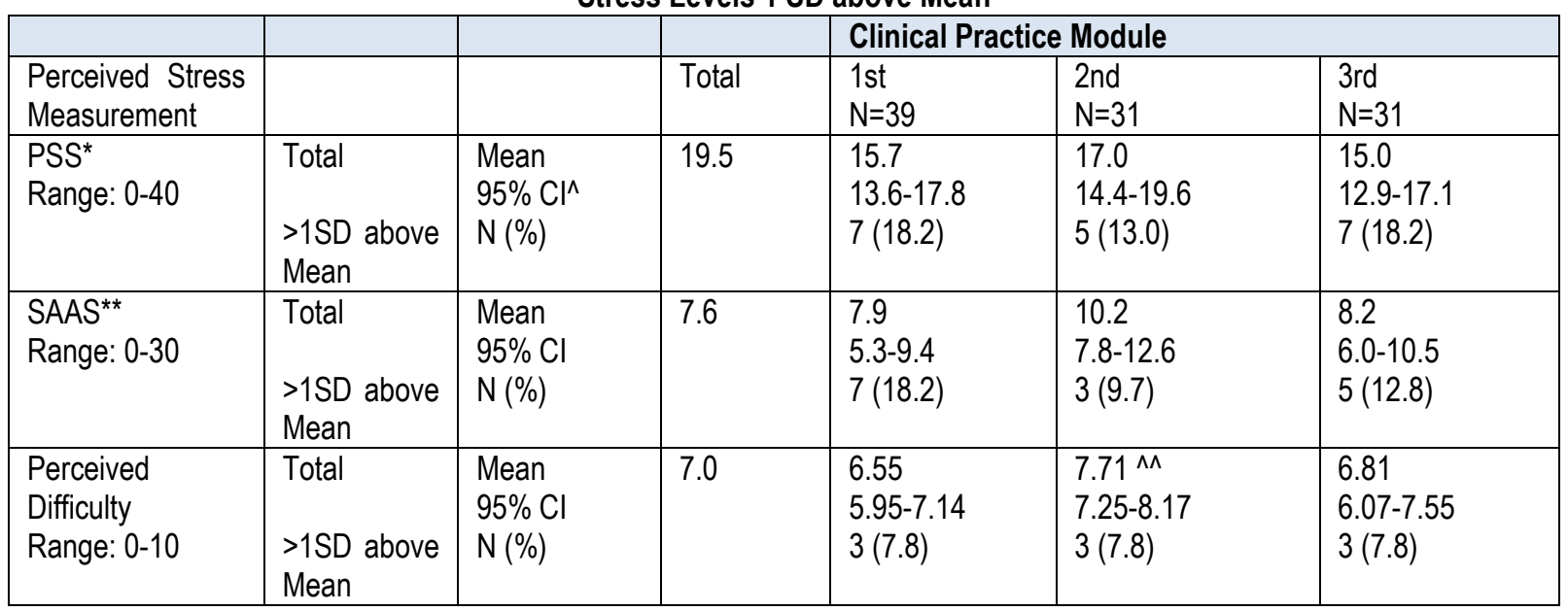

*Perceived Stress Scale; ** Scale for Assessing Academic Stress; ^ Confidence Interval;

$\wedge \wedge$ Significant differences between groups.

Table 3: Correlations between PSS^, SAAS ${ }^{\wedge \wedge}$, Perceived Difficulty ${ }^{\wedge \wedge \wedge}$ and GPA ${ }^{\wedge \wedge \wedge \wedge}$ During Three Clinical Practice Modules

\begin{tabular}{|c|c|c|c|c|c|c|}
\hline & \multicolumn{6}{|c|}{ Clinical Practice Period } \\
\hline & \multicolumn{2}{|c|}{$1^{\text {st }}(n-39)$} & \multicolumn{2}{|c|}{$2^{\text {nd }}(n=31)$} & \multicolumn{2}{|c|}{$3^{\text {rd }}(n=31)$} \\
\hline & $\overline{\text { PSS }^{\wedge}}$ & $\mathrm{SAAS}^{\wedge \Lambda}$ & PSS & $\overline{S A A S}$ & PSS & SAAS \\
\hline SAAS & $.78^{* \star *}$ & & $.85^{* \star \star}$ & & $.81^{* * *}$ & \\
\hline 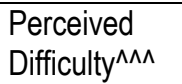 & $.44^{\star *}$ & .19 & $.43^{*}$ & $.55^{* *}$ & $.45^{*}$ & $.49^{* *}$ \\
\hline GPA $2^{\text {nd }}$ year & -.18 & -.08 & -.16 & -.31 & -.24 & -.21 \\
\hline
\end{tabular}

${ }^{\wedge}$ Perceived Stress Scale; ${ }^{\wedge}$ Scale for Assessing Academic Stress;

$\wedge \wedge \wedge$ Perceived difficulty of clinical practice; ${ }^{\wedge \wedge \wedge}$ Grade Point Average

${ }^{* * *} P$ value $<.000 ;{ }^{* *} P$ value $<.001 ;{ }^{*} P$ value $<0.01$

Perceived stress and academic achievements: Pearson correlation between first-year and second-year GPAs was .96, and between third-year and second-year GPAs, it was .64. Both correlations are significant at the 0.01 level (2-tailed). No significant correlations were found between GPA and PSS or SAAS for any of the clinical practice modules.

Perceived stress or difficulty and clinical practice characteristics: Students' PSS and SAAS scores did not differ significantly either between clinical practice modules or between clinical fields. Most students were interested in the clinical field and expressed satisfaction with their assignment, with the clinical guidance, and with the faculty member's availability. No relationship was found between clinical practice characteristics and either PSS, SAAS, or perceived difficulty (Table 1).

The perceived difficulty scores for the second clinical module were significantly higher than those of the first or third modules (Table 2), but no relationship was found between perceived difficulty scores and clinical fields.

Perceived stress and socio-demographic characteristics: The majority of the students were single women in their mid-twenties. During the first clinical practice module, nearly one third of the students changed their place of residence to be closer to the clinical placement, and about $20 \%$ of the entire cohort did so during the second and third modules. About $40 \%$ had to drive more than one hour to the clinical placements. The percent of students who worked for a living during the clinical practice increased over time, from $46.2 \%$ to $74.2 \%$ (Table 1 ). 
Stress Among Bachelor Physical Therapy Students in Israel during Clinical Practice and Its Association with Academic

Analysis of the relationships between socio-demographic variables and PSS or SAAS scores revealed no significant results. Lower levels of perceived difficulty were found among students who worked for living during the clinical practice and among students who changed their place of residence during the third clinical practice module (Table 4).

Table 4: Perceived Difficulty and Students' Socio-Demographic Characteristics (3rd period)

\begin{tabular}{|l|l|l|l|l|l|}
\hline & & \multicolumn{4}{|l|}{ Perceived difficulty } \\
\hline & & N & Mean & 95\% confidence Interval & Sig. \\
\hline Held a job during clinical & Yes & 23 & 6.3 & $5.4-7.1$ & 0.03 \\
practice module & No & 7 & 8.1 & $6.5-9.8$ & \\
\hline Changed place of residence & Yes & 6 & 5.2 & $2.3-8.0$ & 0.03 \\
due to clinical practice site & No & 25 & 7.2 & $6.5-7.9$ & \\
\hline
\end{tabular}

Note: No relationships were observed between perceived difficulty and either gender, family status, driving time to clinical placement, degree of professional interest, or satisfaction with clinical guidance.

Note: No relationships were observed between perceived difficulty and either gender, family status, driving time to clinical placement, degree of professional interest, or satisfaction with clinical guidance.

\section{DISCUSSION}

This longitudinal study provides information about perceived stress and background characteristics of a cohort of bachelor PT students during three compulsory clinical practice periods in Ariel University in Israel. The participants' high response rate and the fact that their age and gender distribution was similar to that of the entire class suggest this group was representative of the target population.

Levels of perceived stress: The degrees of perceived stress as measured by PSS and SAAS were similar throughout the three clinical practice periods, irrespective of the professional field or order of clinical practice modules, students' satisfaction with their clinical experience, students' academic achievements, or their socio-demographic background. The two measures of stress correlated significantly with each other, which points to the validity of the findings.

It may be assumed that students' perceived stress levels evaluated during clinical practice would be higher than during theoretical studies, as was suggested in another study., ${ }^{9,18}$ Indeed, we found that the average mean PSS (15.9) was higher than that of a previous group of 154 bachelor PT students in the same university (13.5; $95 \% \mathrm{Cl}: 12.4-14.6)$, and higher than the norm found among a sample of US undergraduate college students (13.1) evaluated during the theoretical studies module.8,18 This trend was demonstrated also by the mean average SAAS (7.6), which was higher than the norm found in a group of college students (average norms for 50 college boys and girls was 5.24). ${ }^{20}$ However, the latter comparison should be considered carefully because of differences between populations. Comparing the current study's findings with those of a previous study conducted among a group of PT students from the same university reveals that unlike the perceived stress levels (which were higher in the current study), the average mean perceived difficulty level of this cohort (7.0) was similar to that of the previous study (7.7), although the two were evaluated at different periods in the course of the program. ${ }^{8}$ Indeed, the correlation between both perceived stress measurements and perceived difficulty was significant but moderate ( $r$ about 0.5 ), which was not unexpected. Perceived stress and perceived difficulty evaluate different aspects of the individual's psychological state. It is suggested that perceived stress may be an emotional reaction, whereas perceived difficulty may be a more cognitive reaction to a certain situation. ${ }^{4}$ The two phenomena do not necessarily have to match.

Although there is no stress-score threshold for PSS and SAAS, it was assumed that students who presented stress levels higher than the mean by $1 \mathrm{SD}$ would be considered more stressed than their peers. For the most part, it was not the case that the same individual students had the highest perceived stress-related scores in all three clinical practice periods. It is assumed, therefore, that instances of high perceived stress might have been related to other specific circumstantial conditions, such as infelicitous interpersonal relationships or other problems of a personal nature. As students are away from the campus during clinical practice, the availability of psychological services is not satisfactory. Therefore, clinical instructors, who are in daily contact with the students, should be guided to pay attention to signs of stress and how to cope with it in real time. ${ }^{12,24}$ In addition, clinical instructors should be encouraged to contact the faculty member who is in charge of the clinical practice and to seek consultation regarding a particular case of a student with symptoms of high levels of stress. This faculty is familiar with the students and with most of the clinical instructors. She tries to identify potentially vulnerable students and to assign them to clinical placements with experienced and sensitive clinical instructors, so as to minimize personal problems during the clinical practice. Although most students were satisfied with their assignment and with the clinical guidance they received, the percentage of students (16\% to 18\%) with high levels of

(c) The Internet Journal of Allied Health Sciences and Practice, 2016 
perceived stress merits attention. Therefore, it is suggested that more collaboration between the liaising faculty member and the clinical instructors would be helpful. An early identification of stress may be beneficial for students who experience stress and need assistance in order to cope with it successfully. ${ }^{20}$

Perceived stress and academic achievements: The assumption that students with low academic achievements would be more likely to experience high levels of perceived stress was not confirmed in this study. Similar results were observed with regard to entry-level Doctorate PT students in a US university. ${ }^{25}$ Based on these results, it is suggested that there is no justification for changing the policy of avoiding early disclosure of students' personal information to the clinical practice instructors.

Perceived stress and clinical practice characteristics: In contrast to our preliminary assumptions, students' perceived stress levels were similar throughout the three clinical periods, irrespective of their order or field of practice. In addition, the majority of the students were satisfied with their assignments, with the clinical guidance, and with the availability of faculty; consequently, these factors were not related to perceived stress. Therefore, it is suggested that students' perceived stress might be affected by factors other than those evaluated in this study, such as various circumstantial conditions. It may be that the fact that each period takes place in a different facility and location and with different clinical instructors means that each clinical practice presents a fresh challenge for students and hence their perceived stress remains at a constantly high level. These results may lead to the conclusion that participation in clinical practice in general might be a stressful situation, although, in this study, no specific related variables were observed as potential sources of stress.

Perceived stress and socio-demographic characteristics: Similar to previous findings, personal factors such as gender and family status were not related to levels of perceived stress. ${ }^{8}$ In addition, no differences were found between students who held an additional job and those who did not as was described in previous studies. ${ }^{1,8}$ Interestingly, students who held a job while completing their clinical practice assignments indicated lower perceived difficulty levels than did their peers. It is possible that these students had the advantage of a better learning capacity in the first place, and therefore were less likely to experience stress. Another variable, related to low perceived difficulty rates, was the change of residence undertaken by students in order to live closer to the clinical placement. However, driving time to the clinical placement was not related to any of the stress measurements or to perceived difficulty.

Nevertheless, no predisposing factors that can predict high levels of perceived stress during the clinical practice were observed in this study. Possible sources of stress may be related to other factors, such as less-than-optimal interpersonal relationships within the clinical setting, ${ }^{9,13}$ individual personal problems, or learning capacity. It is recommended that clinical instructors receive instructions on ways to identify stress among students as early as possible and on proper ways to react in such circumstances. To identify the real sources of stress, future studies should use qualitative rather than quantitative methods. Such studies may enable discoveries about sources of stress from the students' testimony.

\section{Limitations of the Study}

The results should be carefully interpreted, as the students enrolled in the present study constitute a discrete group of bachelor of PT students in one university in Israel and thus do not represent their peers in other academic institutions in Israel or abroad. In addition, there is no information about the sensitivity of the PSS or the SAAS; therefore, it was impossible to distinguish between high/moderate/low degrees of PS. Furthermore, PSS norms are available only for US students and SAAS norms are available only for high school and college students, while the norms of Israeli university students might be different.

\section{CONCLUSIONS}

Participation in clinical practice in general might be a stressful situation, but none of the factors inherent to the specific structure of this bachelor PT program of studies was identified as a source of stress in this study. It is assumed that perceived stress might be related to other factors, such as interpersonal relationships within the clinical setting or problems of a personal nature.

Further investigation of perceived stress, using various research methods among a larger group of PT students and among PT students from other universities may help increase our understanding of the sources of perceived stress. In the meantime, faculty and clinical instructors should be aware of signs of distress in individual students and try to support them when necessary.

Acknowledgment: The authors would like to thank the students Bosmat Gutman, Michal Linkovsky, Ortal Moyal and Ina Gofman for their contribution in data collection.

(c) The Internet Journal of Allied Health Sciences and Practice, 2016 


\section{REFERENCES}

1. Tucker B, Jones S, Mandy A, Gupta R. Physiotherapy students' sources, perceived course difficulty, and paid employment: comparison between Western Australia and United Kingdom. Physiother Theory Pract. 2006 Dec; 22(6):317-28. [PMID 17166822]

2. Dahlqvist V, Söderberg A, Norberg A. Dealing with stress: Patterns of self-comfort among healthcare students. Nurse Educ Today. 2008 May; 28(4):476-84. [PMID 17868956]

3. Nerdrum P, Rustoen T, Ronnestad MH. Psychological distress among nursing, physiotherapy and occupational therapy students: A longitudinal and predictive study. Scan J Educ Res. 2009;53:363-78.

4. Walsh JM, Feeney C, Hussey J, Donnellan C. Sources of stress and psychological morbidity among undergraduate physiotherapy students. Physiotherapy. 2010 Sep;96(3):206-12. doi: 10.1016/j.physio.2010.01.005. [PMID 20674652]

5. Higgs J, Hunt A, Higgs $C$, Neubauer D. Physiotherapy education in the changing international healthcare and educational context. Advances in Physiotherapy. 1999;1:17-26.

6. Seaward BL. Managing Stress: Principles and Strategies for Health and Wellbeing,8e. Boston, MA: Jones and Barlett; 2013. P.6.

7. Sarid $\mathrm{O}$, Anson $\mathrm{O}$, Yaari A, Margalit M. Academic stress, immunological reaction, and academic performance among students of nursing and physiotherapy. Res Nurs Health. 2004;27(5):370-7. [PMID 15362147]

8. Jacob T, Gummesson C, Remedios L, El-Ansary D, Nordmark E, Webb G. Sources of stress among physiotherapy students: A cross-cultural perspective. JOPTE, 2012;26(3):57-65.

9. May WW, Morgan B, Lenke JC, Stone HL. Model for ability based assessment in physical therapy. JOPTE. 1995;9(1):3-6.

10. Hayes KW, Huber G, Roger J, Sanders B. Behaviors that cause clinical instructors to question the clinical competence of physical therapy students. Phys Ther. 1999 Jul;79(7):653-67; discussion 668-71. [PMID:10416575]

11. Jette DU, Portney LG. Construct validation of a model for professional behavior in physical therapist students. Phys Ther. 2003 May;83(5):432-43. [PMID 12718709]

12. Cupit RL. Student stress: An approach to coping at the interface between preclinical and clinical education. Aust J Physiother. 1988;34(4):215-9. [PMID 25026166]

13. Nakano Y, Yamasaki H, Sakai S, et al. Physical therapy students' stress response after practical training -Focus on the stress event and resilience. Rigakuryoho Kagaku. 2011;26(3):429-33.

14. Jette DU, Nelson L, Palaima M, Wetherbee E. How do we improve quality in clinical education? Examination of structures, processes, and outcomes. JOPTE. 2014;28(S1):6-12.

15. Al-Qaisy LM, Khuffash SR. Relation between personality traits and academic achievement among university students. JESR. 2012; May:2:121-9.

16. Rizzolo D, Zipp GP, Stiskal D, Simpkins S. Stress management strategies for students: The immediate effect of Yoga, humor, and reading on stress. J Coll Teach Learn. 2009;6(8):79-88.

17. Baghurst T, Kelley BC. An examination of stress in college students over the course of a semester. Health Promot Pract. 2014 May;15(3):438-47. [PMID 24231633]

18. Cohen S, Kamarck T, Mermelstein R. A global measure of perceived stress. J Health Soc Behav. 1983 Dec;24(4):385-96. [PMID 6668417]

19. Beck AT, Steer RA, Garbin MG. Psychometric properties of Beck Depression Inventory: Twenty five years of evaluation. Clin Psychol Rev. 1988;8:77-100.

20. Sinha UK, Sharma V, Mahendra K. Development of a scale for assessing academic stress: A preliminary report. JIOM. 2001;23:102-5.

21. Cohen S, Williamson GM. Perceived stress in a probability sample of the United States. In Spacapan S, Oskamp S. (eds.) The Social Psychology of Health. Newbury Park, CA: Sage; 1988.

22. Roberti JW, Harrington LN, Storch EA. Further psychometric support for the 10-item version of the Perceived Stress Scale. JCC. Fall 2006;9:135-47. DOI: 10.1002/j.2161-1882.2006.tb00100.x

23. Hecht TD, McCarthy JM. Coping with employee, family, and students roles: Evidence of dispositional conflict and facilitation tendencies. J Appl Psychol. 2010 Jul; 95(4):631-47. [PMID 20604586]

24. Recker-Hughes C, Buccieri KM, Fitzpatrick Timmerberg J, Stolfi AM. Essential characteristics of quality clinical education experiences: Standards to facilitate student learning. JOPTE. 2014; 28:6-12.

25. Frank LM, Cassady SL. Health and Wellness in entry-level physical therapy students: Are Measures of stress, anxiety, and academic performance related? Cardiopulm Phys Ther J. 2005; 6(4):5-10. 